А. Д. Александров, А. А. Борисенко, В. А. Залгаллер, В. А. Марченко, К. В. Маслов, А. Д. Милка, С. П. Новиков, Ю. Г. Решетняк, И. В. Скрыпник, Е. Я. Хруслов, Алексей Васильевич Погорелов (к восьмидесятилетию со дня рождения), УМН, 1999, том 54, выпуск 4, 188-190

DOI: https://doi.org/10.4213/rm201

Использование Общероссийского математического портала Math-Net.Ru подразумевает, что вы прочитали и согласны с пользовательским соглашением http://www.mathnet.ru/rus/agreement

Параметры загрузки:

IP : 54.198 .64 .247

26 апреля 2023 г., $10: 40: 31$ 


\section{АЛЕКСЕЙ ВАСИЛЬЕВИЧ ПОГОРЕЛОВ}

(к восьмидесятилетию со дня рождения)

3 марта 1999 года исполнилось 80 лет академику Алексею Васильевичу Погорелову.

А.В. Погорелов родился в г. Короча (Белгородская область). Окончил Харьковский государственный университет (ХГУ, 1937-1941) и Военно-воздушную академию им. Н. Е. Жуковского (Москва, 1941-1945). С 1945 года работал в ЦАГИ и одновременно учился в заочной аспирантуре по специальности "геометрия и топология" при Московском государственном университете. Учителями А. В. Погорелова были известные математики и педагоги, создатели отечественной научной школы геометрии "в целом", профессора Н.В. Ефимов и А.Д. Александров. Защитив кандидатскую, а через год и докторскую диссертации, он возвращается в Харьков $(1947$ г.), где вскоре возглавляет кафедру в ХГУ. В 1960 году А.В. Погорелов переходит в Физико-технический институт низких температур АН Украины (ФТИНТ), в котором он по настоящее время руководит отделом геометрии в Математическом отделении. В 1951 году А.В. Погорелов избирается членом-корреспондентом, в 1960 г. академиком АН Украины, с этого же года он - член-корреспондент, а с 1976 г. - академик AH CCCP.

Яркое математическое дарование и незаурядный инженерный талант определили широкий круг научных интересов А. В. Погорелова, охватывающий как фундаментальные, так и прикладные направления. Ему принадлежат решения ряда ключевых проблем в геометрии "в целом", в основаниях геометрии, в теории уравнений Монжа-Ампера, а также замечательные результаты по геометрической теории устойчивости тонких упругих оболочек. Уже первое глубокое исследование Алексея Васильевича - решение восходящей к О. Коши, Д. Гильберту и С.Э. Кон-Фоссену трудной проблемы однозначной определенности общих выпуклых поверхностей их метрикой - выдвинуло его в число ведущих представителей мировой науки. Это научное достижение вызвало качественный подъем в теории нерегулярных поверхностей, начала которой незадолго до этого были заложены А. Д. Александровым. Оно определило приоритеты этой теории на десятилетия вперед.

В дальнейшем А. В. Погореловым были решены и другие сложные проблемы геометрии "в целом", в частности, проблема регулярности выпуклой поверхности с регулярной метрикой, проблема Вейля о реализуемости выпуклой метрики для римановых пространств, проблема бесконечно малых изгибаний выпуклых поверхностей, проблема несобственных выпуклых аффиинных гиперсфер. Им было также получено полное решение четвертой проблемы Гильберта и регулярное решение многомерной проблемы Минковского. Эти работы стимулировали создание нового обширного раздела математических исследований - внешней геометрии выпуклых поверхностей, 
логически завершившего и дополнившего теорию А. Д. Александрова - внутреннюю геометрию выпуклых поверхностей. Они утвердили теорию выпуклых поверхностей как раздел классической дифференциальной геометрии. Им построена теория поверхностей ограниченной внешней кривизны (1956 г.), разработана общая геометрическая теория уравнений Монжа-Ампера для трехмерного (1960 г.) и многомерного (1983 г.) случаев, существенно расширена теория $G$-пространств Г. Буземана (1998 г.).

Совсем недавно А. В. Погорелов нашел полное решение еще одной важной проблемы, доказав равенство дважды дифференцируемых замкнутых выпуклых поверхностей с положительной гауссовой кривизной, второй дифференциал разности опорных функций которых есть знакопеременная форма или тождественно равняется нулю. Эта теорема для случая аналитических поверхностей была установлена еще в 1939 г. А. Д. Александровым. Неоднократные попытки ослабить условие аналитичности до естественного требования дважды дифференцируемости оказывались безуспешными вплоть до 1999 г.

Нужно отметить, что во многих из этих исследований А. В. Погореловым был проявлен исключительный талант не только геометра, но и блестящего аналитика.

А. В. Погорелов развил оригинальный геометрический подходк проблемам устойчивости тонких упругих оболочек и поставил ряд прецизионных экспериментов, подтверждаюших его теорию. Он одним из первых исследователей в СССР (1970 г.) предложил новую идею конструкции синхронного криотурбогенератора со сверхпроводящей обмоткой возбуждения, что послужило толчком в развитии криогенного машиностроения в стране. В дальнейшем А. В. Погорелов принимал активное участие в теоретических расчетах и технических разработках промышленных вариантов криотурбогенераторов, выполнявшшхся во ВТИНТ.

А.В. Погореловым написаны многочисленные монографии, учебники по основным разделам геометрии для высшей школы и известный учебник по геометрии для средних школ, который с 1982 г. является действующим в массовой школе. Книги А.В. Погорелова изложены ясным и четким языком. Они выдержали большое количество изданий в разных странах.

Алексей Васильевич Погорелов удостоен многих наград и званий. Он является обладателем международной премии им. Н.И. Лобачевского, Ленинской премии, Государственных премий Украины и СССР, именных премий Национальной Академии наук Украины. А. В. Погореловзаслуженный деятель науки и кавалер правительственных наград.

Мы от души желаем Алексею Василевичу доброго здоровья, счастья, радости новых творческих достижений.

А. Д. Александров, А. А. Борисенко, В. А. Залгаллер, В. А. Марченко, К. В. Маслов, А.Д. Милка, С. П. Новиков, Ю.Г. Решетняк, И. В. Скрыпник, Е.Я. Хруслов

\section{СПИСОК ПЕЧАТНЫХ РАБОТ А.В. ПОГОРЕЛОВА}

[164] Специальные бесконечно малые изгибания конических поверхностей // Докл. АН СССР. 1988. T. 303. № 3. С. 563-566

[165] Потеря устойчивости развертывающихся оболочек // Докл. АН СССР. 1989. Т. 304. № 5. C. $1056-1059$

[166] Потеря устойчивости конических оболочек под внешним давлением // Докл. АН СССР. 1989. T. 309. № 4. C. 1322-1326

[167] Потеря устойчивости конических оболочек при кручении // Докл. АН СССР. 1989. Т. 309. № 4

[168] Bending of Surfaces and Stability of Shells // Transl. Math. Monographs. V. 72

[169] Об учебнике "Геометрия 7-11" // Математика в школе. 1989. № 5

[170] Геометрия (учебник для 7-11 классов общеобразовательных учреждений). М.: Просвещение, 1990

Начало списка опубликовано: Математика в СССР за сорок лет. 1917-1957 (М.: Физматгиз, 1959. - Т. 2. - С. 547-548), а также: Математика в СССР, 1958-1967 (М.: Наука, 1970. - Т. 2. С. 1052-1053), УМН (1979. - Т. 34, вып. 4(208). - С. 225-226; 1989. - Т. 44, вып. 4(268)). - С. 249). 
[171] $G$-пространства Г. Буземана с римановой метрикой // Докл. АН СССР. 1990. Т. 313. № 5. C. $1044-1046$

[172] Регулярные G-пространства Г. Буземана // Докл. АН СССР. 1990. Т. 314. № 1. С. 114-118

[173] Решение одной проблемы Г. Буземана // Докл. АН СССР. 1990. Т. 314. № 4. С. 790-792

[174] Об одной теореме Бельтрами // Докл. АН СССР. 1991. Т. 316. № 2. С. 297-299

[175] Потеря устойчивости цилиндрических оболочек при неравномерном осевом сжатии // Докл. АН СССР. 1991. Т. 318. № 6. С. 1325-1327

[176] О нижнем пределе критической нагрузки при осевом сжатии цилиндрической оболочки // Докл. АН СССР. 1992. Т. 324. № 3. С. 550-552

[177] Геометрические методы в теории устойчивости оболочек (обзор) // Прикладная механика. 1992. Т. 28. №1. С. 3-22

[178] Generalized solutions of Monge-Ampere equations of elliptic type (review) // A Tribute to Ilya Bakelman. Proc. of a conf. College Station, TX: Texas A\&M University, 1994. P. 47-50 (with I. R. Bakelman et al (ed.))

[179] Вложение "мыльного пузыря" внутрь тетраэдра // Матем. заметки. 1994. Т. 56. № 2. C. $90-93$

[180] Потеря устойчивости общих цилиндрических оболочек при осевом сжатии // Докл. РАН. 1994. Т. 337. № 3. С. $330-331$

[181] Геометрія 7-9. Киів: Освіта, 1994

[182] Геометрія 10-11. Киів: Освіта, 1994

[183] Изгибание выпуклой поверхности в выпуклую с заданным сферическим изображением // Матем. заметки. 1995. Т. 58. № 2. С. 295-300

[184] Monge-Ampere multidimensional equation det $\left\|z_{i j}\right\|=\varphi\left(z_{1}, \ldots, z_{n}, z, x_{1}, \ldots, x_{n}\right) / /$ Rev. Math. Math. Phys. 1995. V. 10. P. 1-103

[185] Исследование плоскости в абсолютной геометрии // Докл. РАН. 1996. Т. 348. № 4. C. $449-451$

[186] Buseman regular G-spaces // Rev. Math. Math. Phys. 1998. V. 10. № 4

[187] Изгибание поверхностей и устойчивость оболочек. Киів: Наукова думка, 1998

[188] Решение одной проблемы А. Д. Александрова // Докл. РАН. 1998. Т. 360. № 3

[189] О теоремах единственности для замкнутых выпуклых поверхностей // Докл. РАН. (в печати) 